\title{
Interaction between Phytochrome B and Gibberellins in Thermoperiodic Responses of Cucumber
}

\author{
Grete Grindal Patil, Vibeke Alm, and Roar Moe \\ Department of Horticulture and Crop Sciences, Agricultural University of Norway, P.O. Box 5022, \\ N-1432 Ås, Norway \\ Olavi Junttila \\ Department of Applied Biology, University of Helsinki, P.O. Box 27, FIN-00014, Finland
}

Additional Index words. Cucumis sativus, DIF, EOD-FR, hypocotyls, lh mutant, phytochrome B, stem elongation

\begin{abstract}
The role of phytochrome in control of stem elongation by daily temperature alternations is unclear. The aim of this work was to study the involvement of phytochrome B in thermoperiodism in cucumber (Cucumis sativus $\mathrm{L}$.), and the interaction with gibberellin (GA). The wild type and the phytochrome B deficient, long-hypocotyl (lh) cucumber mutant were grown under alternating day (DT) and night temperature (NT) and either with or without an exposure to end-of-day far-red light (EOD-FR). Without EOD-FR, hypocotyl and internodes of the wild type plants were shorter under a low DT $\left(19^{\circ} \mathrm{C}\right) /$ high NT $\left(25^{\circ} \mathrm{C}\right)$ (negative DIF) compared with a high DT/low NT regime (positive DIF), while the number of leaves was reduced by $12 \%$. EOD-FR enhanced elongation of hypocotyl and internodes. However, EODFR reduced the effect of alternating temperature on hypocotyl elongation. The $l$ cucumber mutant did not respond to EOD-FR treatments, but internode length was slightly increased by positive compared with negative DIF. The results suggest that phytochrome $B$ is required for a maximum effect of daily temperature alternations on stem elongation in cucumber. Additional $\mathrm{GA}_{4}$ reduced the difference between positive and negative DIF, but it had a minor effect only on the difference between EOD-FR and EOD red light (EOD-R) in the wild type. Plants depleted for endogenous GA by the GA biosynthesis inhibitor paclobutrazol, did not respond at all to DIF or EOD treatments. When seedlings were treated with prohexadione-calcium, which blocks both biosynthesis and inactivation of $\mathbf{G A}_{4}$, response to applied $\mathbf{G A}_{4}$ was enhanced by EOD-FR. The present results suggest that, in cucumber, EOD-FR, and probably also positive DIF, enhances tissue sensitivity to $\mathrm{GA}_{4}$. In addition, catabolism of $\mathrm{GA}_{4}$ can be enhanced by negative DIF.
\end{abstract}

The temperature in the light and dark period of the day affects plant growth. Went (1944) observed that stem length in tomato increased by increasing the day temperature (DT) compared to keeping a constant temperature, and referred to these as a thermoperiodic response. There has been a particular interest in the effect of alternating DT and night temperature (NT) on elongation growth. This is because of the need for alternative methods for applying chemical growth retardants for growth control in many commercial greenhouse crops, some of which have a strong thermoperiodic elongation response (Erwin and Heins, 1995; Myster and Moe, 1995). The plants develop tall stems when the DT is higher than the NT (positive difference between DT and NT, positive DIF), while the stems are often shorter when the DT is lower than the NT (negative DIF).

The physiological understanding of the effect of DIF on stem elongation is fragmented. It is found that the quality of a night interruption or end-of-day (EOD) extension light influences the response to DIF. A treatment with far-red (FR) light decreased the difference in stem elongation between positive and negative DIF as compared to red light (R) (Moe et al., 1991). These effects are mediated primarily through phytochromes (Smith, 1995), a pigment which has been suggested to play a role in mediating the DIF response (Moe and Heins, 1990). Generally, morphological changes in response to negative DIF are very much similar to

Received for publication 4 June 2002. Accepted for publication 1 Apr. 2003. We are thankful to R.E. Kendrick, Wageningen Agricultural University, for support and supplying seeds of the $l h$ mutant and near isogenic cucumber line. We also appreciate the help of $\varnothing$. Nissen in designing the statistical models and M. Siira for patient help with growing the plants. The work was financially supported by the Norwegian Research Council, project number 410.240. the effects of a light source rich in R, while FR and positive DIF give rise to similar tall and elongated plant morphology (Moe and Heins, 1990).

At least five different types of phytochrome encoded by different genes have been identified in Arabidopsis (Quail, 1994; Smith, 1995). Each of these members in the phytochrome family has different roles in developmental processes as well as mediating different specific light responses. Both phytochrome A and B have been proposed to be important for seed germination, while phytochrome B plays a major role in detecting the R and FR light in the environment and in the enhancement of stem elongation by an EOD-FR treatment (Smith, 1995). In addition to phytochrome $\mathrm{B}$, other light-stable phytochromes have also been suggested to be involved in the latter responses to $\mathrm{R}$ and FR light (Smith and Whitelam, 1997). It is reported that phytochrome A has a minor or no role in DIF mediated stem elongation of tomato and potato (Runkle and Pearson, 1998), while a reduced response is found in a phytochrome B mutant of Arabidopsis (Thingnæs et al., In press).

Gibberellin (GA) is required for stem elongation. The effect of DIF on stem elongation is correlated with the endogenous content of GA (Grindal et al., 1998a; Jensen et al., 1996; Nishijima et al., 1997). A tall plant grown under positive DIF contains more of $\mathrm{GA}_{1}$ and its immediate precursors than a short plant grown under negative DIF. Further, a high dose of applied GA neutralizes the differences in elongation under contrasting DIF conditions (Grindal et al., 1998b; Ihlebekk et al., 1995). GA is also required for control of stem extension by light. Phytochrome may regulate the sensitivity to $\mathrm{GA}_{1}$ in the stem tissue as well as the $\mathrm{GA}_{1}$ concentration through an effect on gene transcription 
and $\mathrm{GA}_{1}$ metabolism, and the relative importance of the effect on biosynthesis and sensitivity seems to vary with the plant species (Kamiya and García-Martínez, 1999). The transcript level of a leaf-specific GA 20-oxidase is found to be higher in a transgenic antisense phytochrome B clone of potato (Jackson et al., 2000), while no significant differences in $\mathrm{GA}_{4}$ levels were found between wild type plants and a phytochrome B mutant of cucumber (López-Juez et al., 1995).

The purpose of this study was to investigate the role of phytochrome B in thermoperiodic stem elongation using cucumber as a model plant. The interaction between an EOD-FR light treatment and DIF was therefore compared in the wild type and a long-hypocotyl $(l h)$ phytochrome B specific mutant. $\mathrm{GA}_{4}$ is the endogenous bioactive GA for stem elongation in cucumber (López-Juez et al., 1995), and we have included treatments with $\mathrm{GA}_{4}$ and $\mathrm{GA}$ biosynthesis inhibitors as a mean to study a role of GA in the mechanisms underlying the interaction between alternating DT and NT and EOD-FR light.

\section{Materials and Methods}

INTRODUCTORY STUDY. Seeds of the cucumber (Cucumis sativus L.) Ih mutant (Adamse et al., 1987; López-Juez et al., 1992) and a near isogenic wild type line were germinated on wet filter paper for $2 \mathrm{~d}$, then planted in pots with peat (standard fertilized and limed peat, Floralux, Nittedal Torvindustrier, Norway) and grown at 20 to $22{ }^{\circ} \mathrm{C}$ until the hypocotyl hook was open (1 to $2 \mathrm{~d}$ ).

The experiment were carried out in a phytotron with light from high pressure metal halogen lamps (General Electric, MBID 400/ $\mathrm{T} / \mathrm{H}$, USA) supplied during a photoperiod of $12 \mathrm{~h}$ at a $P P F D$ level of $200 \mu \mathrm{mol} \cdot \mathrm{m}^{-2} \cdot \mathrm{s}^{-1}$ (R FR ratio of 1.8$)$. Two growth rooms were used for establishing two combinations of DT and NT. Positive DIF conditions (DT $>$ NT) were created by a DT/NT of $25 / 19^{\circ} \mathrm{C}$ with a corresponding negative DIF (DT < NT) of $19 / 25^{\circ} \mathrm{C}$, both providing an average temperature of $22^{\circ} \mathrm{C}$. The actual temperature varied at maximum $\pm 0.4^{\circ} \mathrm{C}$ from the set point temperature. The wind speed was kept at 0.3 to $0.4 \mathrm{~m} \cdot \mathrm{s}^{-1}$ to avoid an increase in leaf temperature. The actual leaf temperature was $0.5^{\circ} \mathrm{C}$ higher than the air temperature during the day period regardless of the air temperature (detected by IRt/cTM infrared thermocouples, Exergene, USA). The water vapor deficit was $0.60 \mathrm{kPa}$ with a maximal deviation of $\pm 0.10 \mathrm{kPa}$. The interaction between the temperature alternations and the effect EOD-FR treatment was tested by physically dividing the cabinets in two parts with several layers of light reflecting material. Thirty minutes of light from FR fluorescent light tubes (No. 7080, from Sylvania BioSystems, van Lieburg and Kendrick, 1996) was supplied in one of the compartments. The FR photon flux at the top of the plants was 0.65 to 0.85 $\mu \mathrm{mol} \cdot \mathrm{m}^{-2} \cdot \mathrm{S}^{-1}$ (detected by SKR 110 and 100: 660/730, Radiation detector and measuring unit, Sky Instruments Ltd., U.K.). The plants were watered daily with a complete nutrient solution, and the final recordings noted after $21 \mathrm{~d}$.

Studies on application of GA AND GA inhibitors. Plants treated with paclobutrazol and prohexadione-calcium were used in addition to nontreated plants to test the effect of GA on hypocotyl length under contrasting DIF treatments and EOD-FR light. Paclobutrazol was applied after germinating the seeds for 2 $\mathrm{d}$ on wet filter paper by soaking them for $2 \mathrm{~h}$ in a solution of 100 $\mathrm{mg} \cdot \mathrm{L}^{-1}$ (Bonzi, Zeneca Agrochemicals LTD., U.K.). The seeds were then transferred to peat and grown for 7 more days. Plants treated with prohexadione-calcium were germinated for $2 \mathrm{~d}$ on filter paper soaked in $500 \mathrm{mg} \cdot \mathrm{L}^{-1}$ prohexadione-calcium $(10 \%$ granulate dissolved in $\mathrm{NaOH}$ and diluted in water), potted and grown for 3 more days before start of the experiments. These plants were further sprayed every second day with $250 \mathrm{mg} \cdot \mathrm{L}^{-1}$ prohexadione-calcium.

The plants were grown in two growth cabinets under the same experimental design, temperature combinations, daylength and EOD treatments as in the introductory study, except that the FR tubes were wrapped with red (Primary red, No. 106, LEE Filters, U.K.) and green plastic filters (Dark green, No. 124) to remove peaks in the blue region, and the light level was kept at $0.8 \mu \mathrm{mol} \cdot \mathrm{m}^{-2} \cdot \mathrm{s}^{-1}$. A 30-min EOD-R (Philips TLD 36W/15) was used as a contrasting treatment to EOD-FR. Photosynthetic fluorescent light $\left(210 \mu \mathrm{mol} \cdot \mathrm{m}^{-2} \cdot \mathrm{s}^{-1}\right)$ was added with tubes from General Electric (F96T12/CW/1500) and enriched with FR light to a R:FR ratio of 1.8 with incandescent lamps. $\mathrm{GA}_{4}$ (Sigma Chemicals) was dissolved in ethanol and diluted to $30 \%$ with water, and added to the base of the cotyledon in drops of $2 \mu \mathrm{L} 1$ to $2 \mathrm{~h}$ before the start of the temperature treatments. The plants were kept at $22{ }^{\circ} \mathrm{C}$ until the drops had dried out. Experiments were terminated after $14 \mathrm{~d}$.

STATISTICAL TREATMENT. In the introductory study the data were analyzed by a split-plot design (ANOVA) based on average values (of six plants) of two experiments repeated in time. DIF and light treatment were considered the main plots and genotype the subplot, and DIF was tested against DIF $\times$ repetition in time. Logarithmic transformed data were used to analyze stem, hypocotyl, internode and petiole length in order to account for the difference in variance among the treatments and between the genotypes, while untransformed data were used for number of leaves.

In the studies on GA the hypocotyl lengths were analyzed (ANOVA) according to a split-split-plot design based on average values (of eight plants) of two experiments repeated in time (REP) with DIF as main-plots, EOD treatment as subplots and GA treatment as sub-sub-plot. Effect of DIF was tested against DIF $\times$ REP, EOD and DIF $\times$ EOD against their pooled interactions with REP, and GA, DIF $\times$ GA, EOD $\times$ GA and DIF $\times$ EOD $\times$ GA against the pooled remaining interactions with $\mathrm{REP}$. DIF $\times \mathrm{EOD} \times \mathrm{GA}$ was not significant at $5 \%$ level for any recording. Whenever only one replication is presented, standard error of the mean is given.

\section{Results}

INTRODUCTORY STUDY. Wild type cucumber plants grown for three weeks under negative DIF developed $65 \%$ shorter stems compared to plants under positive DIF(Fig. 1). Exposing the plants

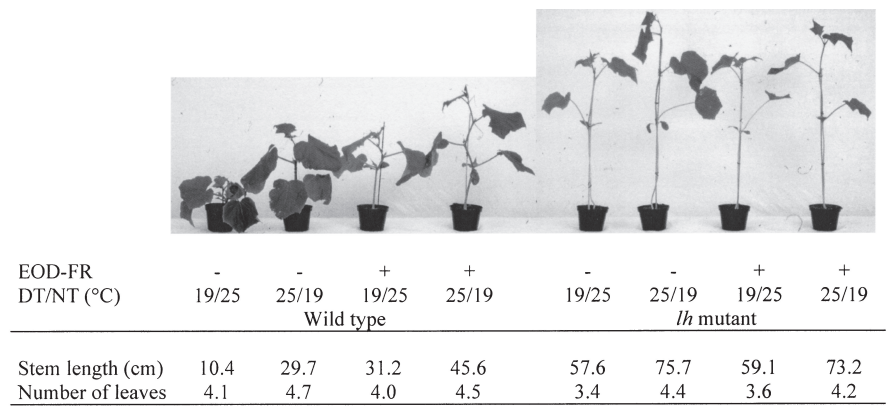

Fig. 1.Effect of 30-min end-of-day far-red light(EOD-FR) enriched light treatment on morphology of cucumber (wild type and $l h$ mutant) grown for $21 \mathrm{~d}$ under day and night temperature (DT/NT) combinations as indicated. Stem length was significantly affected by temperature $(P \leq 0.001)$, EOD-treatment $(P=$ $0.001)$ and genotype $(P \leq 0.001)$ and their interactions (all $P$ values $\leq 0.011)$, while number of leaves was only affected by temperature $(P=0.014)$ and genotype $(P=0.031)$. 

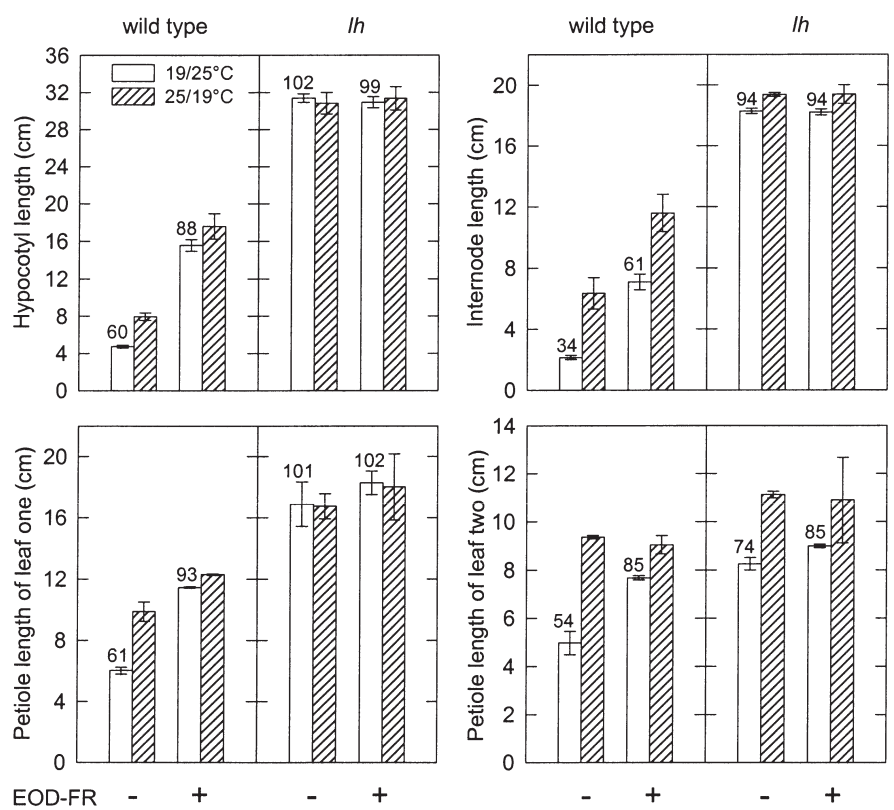

to EOD-FR enriched light enhanced stem elongation under both temperature regimes (Fig. 1). However, EOD-FR light enhanced the stem length more under negative than positive DIF and thereby reduced the inhibitory effect of negative DIF from $65 \%$ to $31 \%$. The stems of the $l h$ mutant were $24 \%$ shorter under negative than positive DIF without additional EOD-FR light (Fig. 1). The stem length in this mutant was not affected by the exposure to FR (Fig.

1 ), and therefore, the effect of DIF was not altered by the FR treatment.

The number of fully unfolded and unfolding leaves was lower( $11 \%$ to $23 \%$ ) under negative than positive DIF, and higher in the wild type than in the $l h$ mutant (Fig. 1). The hypocotyl, the first internode and the petiole of the first and second leaves were significantly shorter in wild type plants grown under negative than positive DIF when no FR was added (Fig. 2). Exposure to EOD-FR light, nullified the difference in response to positive and negative DIF conditions. In contrast, the same characters in the $l h$ mutant, except for the second petiole, were hardly affected by DIF or by an exposure to EOD-FR (Fig. 2).

In a corresponding study, plants were grown under the same temperature regimes as described above, but exposed to a 12-h $\mathrm{R}$ or FR enriched treatment prolonging the 12-h high intensity light period. This test gave the same results as above (data not shown). The

Fig. 3. Effect of applied $\mathrm{GA}_{4}$ on increase in hypocotyl length of wild type cucumber plants, either treated with no GA biosynthesis inhibitor or with paclobutrazol, grown under alternating day and night temperatures (DT/NT) and in combination with a 30-min end-ofday far-red (EOD-FR) or end-of-day red (EOD-R) light treatment. For the nontreated plants main effects of temperature (T), EOD- and GA-treatment were statistically different at $P \leq 0.001$, while only interactions between $\mathrm{T} \times \mathrm{EOD}(P=0.015)$ and $\mathrm{EOD}$ $\times \mathrm{GA}(P=0.001)$ were different. SE is indicated as bars for the paclobutrazol plants where the experiment was run once ( $\mathrm{n}=8$ plants).

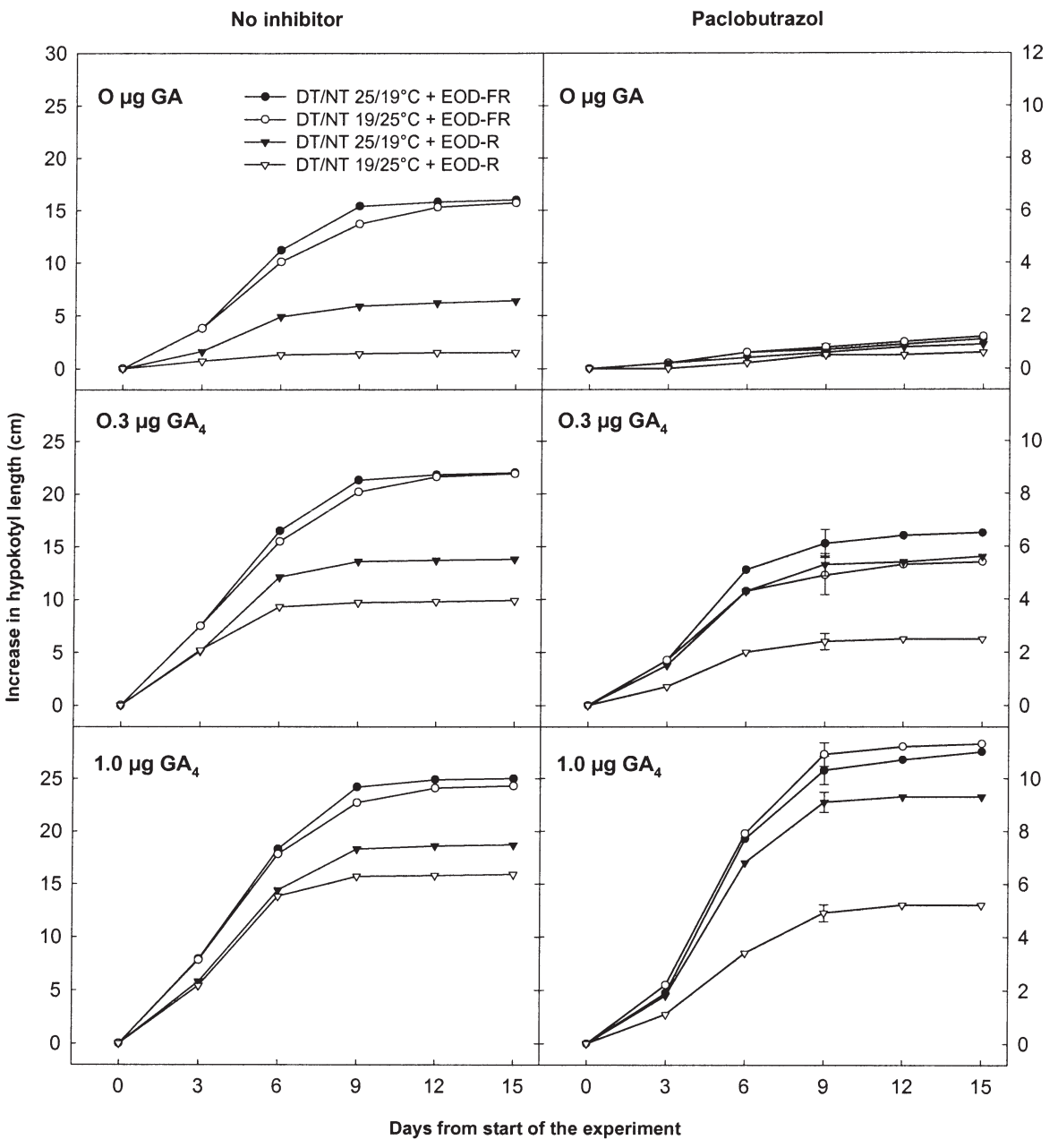

FR light counteracted the relative difference between positive and negative DIF in the wild type, while there was no significant effect of DIF on the length of hypocotyl and first internode in the $l h$ mutant.

STUdies ON APPLICATION OF GA AND GA INHIBITORS. The hypocotyls of cucumber are fast growing and with a strong response to DIF and EOD-FR, and were therefore chosen to further study the interaction with GA. Hypocotyl elongation of wild type plants exposed to EOD-R light was greater under positive than negative DIF (Fig. 3). Hypocotyls under negative DIF reached maximum elongation rates during days 0 to 3 at start of the experiment, while under positive DIF they grew fastest during days 4 to 6 . With EOD-FR light the hypocotyls reached the maximum elongation rate at days 4 to 6 under both positive DIF and EOD-R. $\mathrm{GA}_{4}$ application to the base of the cotyledon at the start of the experiment strongly increased elongation underEOD-R light, and on length of hypocotyl, first developed internode and petiole of first and second true leaf of wild type and $l h$ mutant of cucumber grown for $21 \mathrm{~d}$ under day elongation response under negative / positive DIF $\times 100$ is given at the top of the bars. SE of mean of two experiments is indicated as \pm values. The following
significantly differences of temperature (T), EOD treatment (EOD) and genotype $(\mathrm{G})$ and their interactions were found:

\begin{tabular}{lccccccc} 
& $\mathrm{T}$ & $\mathrm{EOD}$ & $\mathrm{G}$ & $\mathrm{T} \times \mathrm{EOD}$ & $\mathrm{T} \times \mathrm{G}$ & $\mathrm{EOD} \times \mathrm{G}$ & $\mathrm{T} \times \mathrm{EOD} \times \mathrm{G}$ \\
\hline Hypocotyl & $<0.001$ & $<0.001$ & $<0.001$ & $<0.001$ & 0.018 & $<0.001$ & 0.060 \\
Internode & 0.007 & 0.006 & $<0.001$ & ns & 0.003 & 0.002 & 0.044 \\
Petiole (1) & NS & 0.020 & $<0.001$ & NS & 0.013 & 0.007 & 0.040 \\
Petiole (2) & 0.011 & NS & 0.006 & NS & NS & Ns & Ns
\end{tabular}




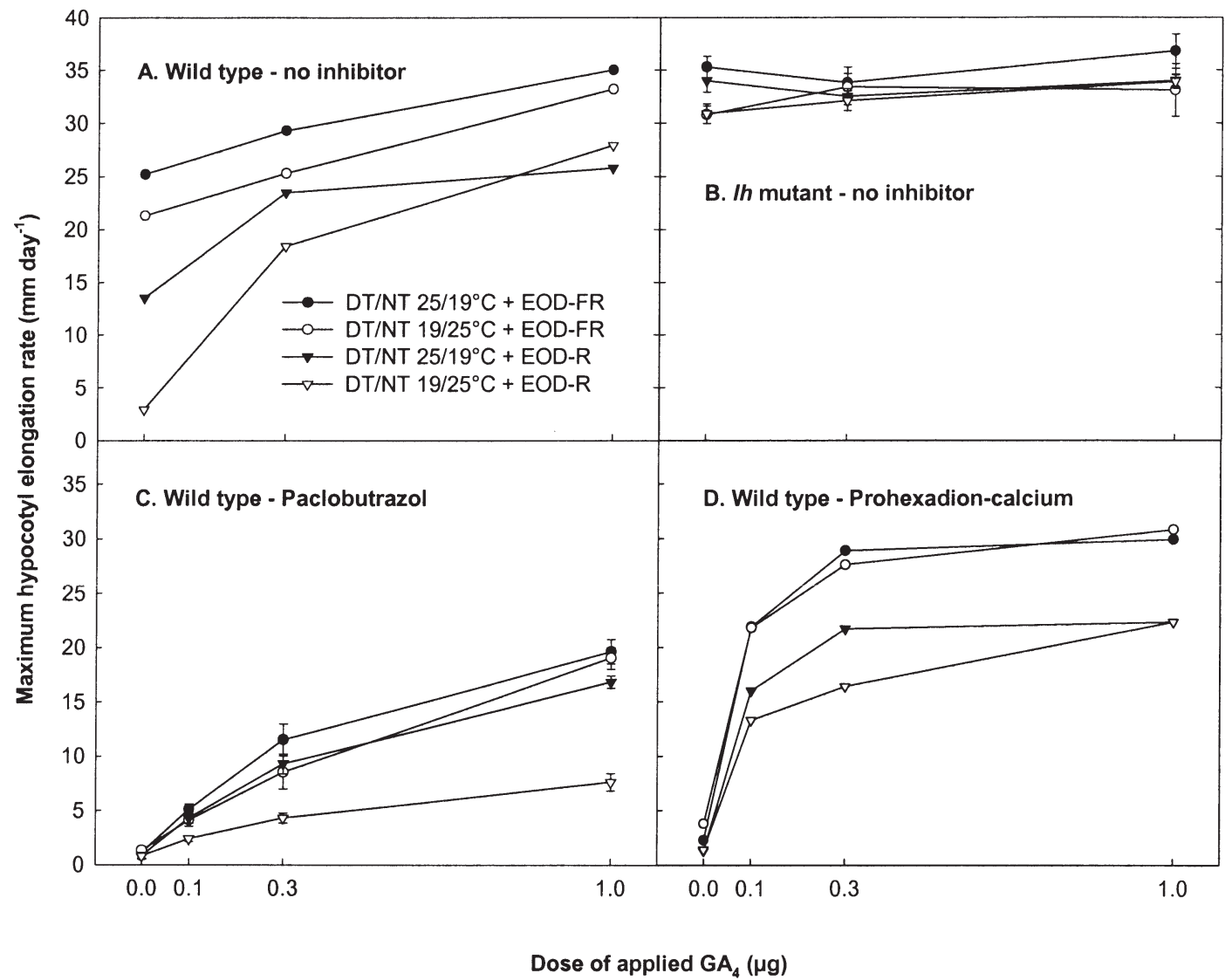

Fig. 4. Maximum hypocotyl elongation rate in response to applied $\mathrm{GA}_{4}$ in wild type plants of cucumber $(\mathbf{A})$, $l h$ mutant $(\mathbf{B})$, and wild type plants treated with either paclobutrazol (C) or prohexadion-calcium (D) and grown under alternating day and night temperatures (DT/NT) and in combination with a 30-min of end-of-day far-red (EOD-FR) or end-of-day red (EOD-R) light treatment. The experiment was repeated once in experiment $\mathbf{A}$ and $\mathbf{D}$ and the main effects of temperature (T), EOD- and GA-treatment and their interactions were statistically different at $P \leq 0.05$ except for $\mathrm{T} \times \mathrm{GA}(P=0.062)$. sE is indicated as bars for experiment $\mathbf{B}$ and $\mathrm{C}$ where the experiment was run once ( $\mathrm{n}=8$ plants).

the difference in hypocotyl length between negative and positive DIF was visible on days 6 and 9 after treatment with 0.3 and 1.0 $\mu \mathrm{g} \mathrm{GA}_{4}$, respectively (Fig. 3). Hypocotyls under EOD-FR also increased in length $\left(60 \%\right.$ for $\left.1.0 \mu \mathrm{g} \mathrm{GA}_{4}\right)$ in response to $\mathrm{GA}_{4}$, but the relation between negative and positive DIF was not affected. Hypocotyls of plants treated with $\mathrm{GA}_{4}$ elongated fastest during days 4 to 6 under all conditions, except under negative DIF and EOD-R light where $1.0 \mu \mathrm{g} \mathrm{GA}_{4}$ was needed to reach maximum elongation (Fig. 3). There was no difference in maximum elongation rate between negative and positive DIF under EOD-R light when $1.0 \mu \mathrm{g} \mathrm{GA}_{4}$ was added, while the difference between EOD-R and EOD-FR light was still present (Fig. 4A).

The $l h$ mutant grew rapidly from start of the experiment until day 9 , and the most active growth was recorded during days 4 to 6 and 1 to 6 with or without $\mathrm{GA}_{4}$, respectively (data not shown). When no $\mathrm{GA}_{4}$ was added, the maximum elongation rate was slightly higher under positive than negative DIF regardless of EOD-treatment, while light quality had no effect (Fig. 4B). There were no systematic differences among the treatments when $\mathrm{GA}_{4}$ was added.

Pretreatment with paclobutrazol (inhibits early stages of GA biosynthesis) almost completely inhibited growth of the wild type cucumber hypocotyls under any of the growing conditions applied (Fig. 3). The response to exogenous $\mathrm{GA}_{4}$ was much stronger at positive than negative DIF under the EOD-R treatment. The effect of $\mathrm{GA}_{4}$ was stronger under EOD-FR than EOD-R light, but there was no difference between the temperature regimes under the FR light treatment. Hypocotyl length (Fig. 3) and the maximum elongation rate (Fig. 4C) increased with increasing the dose from 0.3 to $1.0 \mu \mathrm{g} \mathrm{GA}_{4}$, suggesting that saturating conditions were not reached under any growing conditions. We tested the response to a dose of $3.0 \mu \mathrm{g}$ in a later experiment and found still a somewhat lower response under negative than under positive DIF with EOD$\mathrm{R}$, although elongation was close to saturation. The most rapid elongation was observed during days 4 to 6 under all conditions when 0.3 and $1.0 \mu \mathrm{g} \mathrm{GA}_{4}$ was added to paclobutrazol treated plants (data not shown). $\mathrm{GA}_{9}$ was tested at doses of $0.3,1.0$, and $3.0 \mu \mathrm{g}$ and the results were comparable to those with $\mathrm{GA}_{4}$.

Hypocotyls of wild type plants treated with prohexadionecalcium (inhibiting $3 \beta$ - and $2 \beta$-hydroxylases) hardly elongated during the 14-d experimental period (Fig. 4D). After EOD-R, the hypocotyls elongated more under positive than negative DIF in response to 0.1 and $0.3 \mu \mathrm{g} \mathrm{GA}_{4}$, but there was no difference with $1.0 \mu \mathrm{g} \mathrm{GA}_{4}$. No difference between negative and positive DIF was present under EOD-FR at any dose of $\mathrm{GA}_{4}$. This suggests that the response, in terms of elongation rate, had reached saturation under both light conditions and there was no difference in elongation under the two temperature regimes in any case. Thus, a saturating $\mathrm{GA}_{4}$ dose could not compensate for EOD-FR. The maximum elongation rate was observed during days 4 to 6 under all conditions when $\mathrm{GA}_{4}$ was applied.

\section{Discussion}

Thermoperiodic responses have been reported earlier in cucumber (Agrawal et al., 1993; Grimstad and Frimanslund, 1993). 
The plants grow taller under a DT higher than the NT (positive DIF) than under a DT lower than the NT (negative DIF), as also shown in the present experiments (Fig. 1). Most species responding to DIF develop a slightly lower number of leaves under negative than positive DIF (Erwin and Heins, 1995; Myster and Moe, 1995). In the wild type cucumber we found up to $12 \%$ fewer leaves in plants grown under negative than positive DIF (Fig. 1). Agrawal et al. (1993) have earlier reported 32\%, while Grimstad and Frimanslund (1993) found only 4\% (not statistically significant) lower node number under negative than positive DIF. In our case, not only the length of fully developed hypocotyls and internodes determined stem length, but also the leaf unfolding rate and thereby the elongation of the upper internodes (Fig. 1). Other morphological characters such as the petiole length (Fig. 2), are also generally affected by DIF.

The effect of DIF is dependent on the light quality of a day extension treatment. In Campanula isophylla (Moe et al., 1991), exposure to FR instead of R throughout the whole night period decreased the effect of negative compared to positive DIF. In the present study we tested the response to DIF in plants grown with or without an exposure to EOD-FR (Figs. 1 and 2) since this is a well studied response to light quality thought to be mediated mainly by phytochrome B but also partly by other light stable phytochromes (Smith, 1995; Smith and Whitelam, 1997). The EOD-FR light treatment eliminated the difference between positive and negative DIF on hypocotyl length in wild type plants of cucumber (Fig. 2). This interaction between DIF and the EOD-FR response is consistent with findings by Downs et al. (1957) in Phaseolus vulgaris. We found no effect of an EOD-FR treatment (Figs. 1-2) in the lh mutant, which is characteristic for this mutant (López-Juez et al., 1992).

The lack of a response to DIF on hypocotyl length in the $l h$ mutant further points to an interaction between DIF and phytochrome B (Fig. 2). However, the fact that a minor DIF response was found in internodes of the $l h$ mutant (Figs. 1 and 2) and the presence of a small DIF response under EOD-FR in the wild type suggest the presence of a minor phytochrome B independent component. The presence of phytochrome B seems therefore to be a prerequisite for a complete response to DIF in cucumber, in particularly in young seedlings, while it may only have a quantitative role at a later developmental stage since some effect of DIF is observed on older tissue (Xiong et al., 2002). Thingnæs (2003) has found a response to DIF in a phytochrome B mutant of Arabidopsis, although it was significantly weaker than in the corresponding wild type. The importance of phytochrome B for a thermoperiodic response may therefore be species dependent, and modified by developmental stage and by other light stable phytochromes.

The wild type cucumber plants grown under negative DIF responded stronger to an application of $\mathrm{GA}_{4}$ than those under positive DIF (Figs. 3 and 4). This is earlier found in Fuchsia ×hybrida (Tangerås, 1979), C. isophylla (Ihlebekk et al., 1995; Moe, 1990) and pea (Grindal et al., 1998b). When removing the background of endogenous GA by inhibiting its synthesis with paclobutrazol, it is clearly shown that plants under positive DIF have a stronger response to GA under positive than negative DIF (Fig. 3) (Grindal et al., 1998b). The effect of DIF on stem elongation is correlated with the $\mathrm{GA}_{1}$ content in $C$. isophylla (Jensen et al., 1996), Dendranthema (Nisijima et al., 1997) and in stem tissue of pea (Grindal et al., 1998a) and the levels of precursors to $\mathrm{GA}_{1}$ (i.e. $\mathrm{GA}_{53}, \mathrm{GA}_{44}, \mathrm{GA}_{19}$, and $\mathrm{GA}_{20}$ ) were also lower under negative than positive DIF. The GAcontent in species where $\mathrm{GA}_{4}$ is the bioactive GA is only available in Arabidopsis (Thingnæs et al., In press). This model plant has a much weaker DIF response than cucumber and showed a weak effect of DIF on the $\mathrm{GA}_{4}$ content.

Grindal et al. (1998a) suggested that pea plants control the $\mathrm{GA}_{1}$ content by inactivating it more under negative than positive DIF. The background for this was that the content of the inactivated form of $\mathrm{GA}_{1}, \mathrm{GA}_{8}$, was higher in pea plants grown under negative than positive DIF (Grindal et al. 1998a). This was supported by the fact that adding $\mathrm{GA}_{1}$ to pea plants in combination with prohexadione-calcium, an inhibitor of the $\mathrm{GA}_{1}$ biosynthesis ( $3 \beta$-hydroxylation) and $\mathrm{GA}_{1}$ inactivation ( $2 \beta$-hydroxylation), the elongation was equally strong under positive and negative DIF (Grindal et al., 1998b). Similar experiments with cucumber (Fig. 4D) showed that the difference in maximum elongation rate between the two temperature treatments was dependent on the GA dose, and it was present at a low $(0.3 \mu \mathrm{g})$ but not at a high (1.0 $\mu \mathrm{g})$ dose. We do not know if $2 \beta$-hydroxylase (2-oxidase) was fully inhibited by the prohexadione-calcium, but the results may indicate that inactivation of $\mathrm{GA}_{4}$ may play a role in a possible thermoperiodic control of the $\mathrm{GA}_{4}$ level in cucumber. No difference in elongation response under a combined prohexadione-calcium and $\mathrm{GA}_{1}$ treatment indicates that the tissue sensitivity plays a minor role in controlling thermoperiodic stem elongation in pea (Grindal et al., 1998b). The hypothesis on an effect of negative DIF on the inactivation of $\mathrm{GA}_{1}$ in pea is confirmed (Stavang and Moe, unpublished data).

EOD-FR light may modify both the tissue concentration and the tissue sensitivity to GA (Kamiya and García-Martínez, 1999). $\mathrm{GA}_{4}$ had minor effects on hypocotyl elongation rates in the phytochrome B deficient $l h$ mutant (Fig. 4B), indicating that lack of a functional phytochrome gives a constitutive GA-response. López-Juez et al. (1995) have investigated the relationship between GA and FR light in the $l h$ mutant of cucumber and suggested that FR light affects the tissue sensitivity to GA in this species. They further hypothesized that FR light modifies the processes late in the GA signal pathway.

In the present experiments, the effect of $\mathrm{GA}_{4}$ and DIF on the maximum elongation rate in wild type cucumber was more or less additive under EOD-FR. Under EOD-R the difference between negative and positive DIF was nullified at the highest dose $(1 \mu \mathrm{g})$ of $\mathrm{GA}_{4}$ (Fig. 4A), but could not match the elongation rate under EOD-FR. These interactions were studied further using plants depleted of endogenous GA (Figs. 3 and 4C) and blocked for both late biosynthetic steps and inactivation of $\mathrm{GA}_{4}$ (Fig. 4D). Together, these studies indicated thatEOD-FR enhanced sensitivity to $\mathrm{GA}_{4}$ and completely over-rode the effect of thermoperiodicity. Together with the findings by López-Juez et al. (1995), this may favor the hypothesis that altered tissue sensitivity by light quality mainly is responsible for the interaction between DIF and EOD-FR. One way to interpret the interaction between DIF and EOD-FR in the wild type plant could be that FR maximizes stem elongation by increasing the response to GA, and thereby hiding the potential effect of DIF on hypocotyl and internode length. Enhanced inactivation of $\mathrm{GA}_{4}$ under negative DIF cannot, however, be excluded as a possible basis for interaction between DIF and $\mathrm{GA}_{4}$ under EOD-R (Fig. 4D).

In conclusion, the present results suggest that the lack of functional phytochrome B almost completely eliminates thermoperiodic stem elongation response in cucumber, and the response is weakened when the phytochrome is converted to the inactive form (Pr) at the beginning of the dark period. The present results 
also indicate that the interaction between DIF and light quality is caused by an increased sensitivity to $\mathrm{GA}_{4}$ under EOD-FR compared with EOD-R. To our knowledge there are no GA mutants available in cucumber, but analysis of endogenous GAs or gene expression studies is needed to see if there is any possible interaction between DIF and light quality on the GA metabolism.

\section{Literature Cited}

Adamse, P., P.A.P.M. Japers, R.E. Kendrick, and M. Koornneef. 1987. Photomorphogenetic responses of a long hypocotyl mutant of Cucumis sativus L. Plant Physiol. 127:481-491.

Agrawal, M., D.T Krizek, S.B. Agrawal, G.F. Kramer, E.H. Lee, R.M. Mirecki, and R.A. Rowland. 1993. Influence of inverse day/night temperature on ozone sensitivity and selected morphological and physiological responses in cucumber. J. Amer. Soc. Hort. Sci. 118: 649-654.

Downs, R.J., S.B. Hendricks, and H.A. Borthwick. 1957. Photoreversible control of elongation of pinto beans and other plants under normal conditions of growth. Bot. Gaz. 118:199-208.

Erwin, J.E. and R.D. Heins. 1995. Thermomorphogenic responses in stem and leaf development. HortScience 30:940-949.

Grimstad, S.O. and E. Frimanslund. 1993. Effect of different day and night temperature regimes on greenhouse cucumber young plant production, flower bud formation and early yield. Scientia Hort. 53:191-204.

Grindal, G., A. Ernstsen, J.B. Reid, O. Junttila, and R. Moe. 1998a. Endogenous gibberellin $\mathrm{A}_{1}$ levels control thermoperiodic stem elongation in Pisum sativum L. Physiol Plant. 102:523-531.

Grindal, G., O. Junttila, J.B. Reid, and R. Moe. 1998b. The response to gibberellin in Pisum sativum grown under alternating day and night temperature. J. Plant Growth Regul. 17:161-167.

Ihlebekk, H., S. Eilertsen, O. Junttila, G. Grindal, and R. Moe. 1995. Control of plant height in Campanula isophylla by temperature alternations; involvement of GAs. Acta Hort. 394:347-355.

Jackson, S.D., P.E. James, E. Carrera, S. Prat, and B. Thomas. 2000. Regulation of transcript levels of a potato gibberellin 20-oxidase gene by light and phytochrome B. Plant Physiol. 124:423-430.

Jensen, E., S. Eilertsen, A. Ernstsen, O. Junttila, and R. Moe. 1996. Thermoperiodic control of stem elongation and endogenous gibberellins in Campanula isophylla. J. Plant Growth Regul. 15:167-171.

Kamiya, Y. and J.L. García-Martínez. 1999. Regulation of gibberellin biosynthesis by light. Cur. Opin. Plant Biol. 2:398-403.

López-Juez, E., A. Nagatani, K.-I. Tomizawa, M. Deak, R. Kern, R.E. Kendrick, and M. Furuya. 1992. The cucumber long hypocotyl mutant lacks a light-stable PHYB-like phytochrome. Plant Cell 4:241-251.

López-Juez, E., M. Kobayashi, A. Sakurai, Y. Kamiya, and R.E. Kend- rick. 1995. Phytochrome, gibberellins, and hypocotyl growth. A study using the cucumber (Cucumis sativus L.) long hypocotyl mutant. Plant Physiol. 107:131-140.

Moe, R. 1990. Effect of day and night temperature alternations and of plant growth regulators on stem elongation and flowering of the longday plant Campanula isophylla Moretti. Scientia Hort. 43:291-305.

Moe, R. and R. Heins. 1990. Control of plant morphogenesis and flowering by light quality and temperature. Acta Hort. 272:81-90.

Moe, R., R.D. Heins, and J. Erwin. 1991. Stem elongation and flowering of the long-day plant Campanula isophylla Moretti in response to day and night temperature alternations and light quality. Scientia Hort. 48:141-151.

Myster, J. and R. Moe. 1995. Effect of diurnal temperature alternations on plant morphology in some greenhouse crops-A mini review. Scientia Hort. 62:205-215.

Nishijima, T., M. Nonaka, M. Koshioka, H. Ikeda, M. Dozono, H. Yamazaki, and L.N. Mander. 1997. The role of gibberellin in the thermoperiodic regulation of stem elongation in Dendranthema gradiflorum Tzvelev. Biosci. Biotechnol. Biochem. 61:675-679.

Quail, P.H. 1994. Phytochrome genes and their expression, p. 71-104. In: R.E. Kendrick and G.H.M. Kronenberg (eds.). Photomorphogenesis in plants. 2nd ed. Kluwer Academic Publishers, Dordrecht, The Netherlands.

Runkle, E.S. and S. Pearson. 1998. Phytochrome A does not mediate reduced stem extension from cool day-temperature treatments. Physiol. Plant 104:596-602.

Smith, H. 1995. Physiological and ecological function within the phytochrome family. Annu. Rev. Plant Physiol. Plant Mol. Biol. 46: 289-315.

Smith, H. and G.C. Whitelam. 1997. The shade avoidance syndrome: multiple responses mediated by multiple phytochromes. Plant Cell Environ. 20:840-844.

Tangerås, H. 1979. Modifying effects of ancymidol and gibberellin on temperature induced elongation in Fuchsia $\times$ hybrida. Acta Hort. 91: 411-417.

Thingnæs, E., S. Torre, A. Ernstsen, and R. Moe. Day and night temperature responses in Arabidopsis. Effects of GA and auxin content, cell size, morphology and flowering time. Ann. Bot. (in press).

van Lieburg, R. and R.E. Kendrick. 1996. A new source of daylight. Chron. Hort. 36:19-20.

Went, F.W. 1944. Plant growth under controlled conditions. II. Thermoperiodicity in growth and fruiting of the tomato. Amer. J. Bot. 31: $135-150$

Xiong, J., G.G. Patil, and R. Moe. 2002. Effect of DIF and end-of-day light quality on stem elongation in Cucumis sativus. Scientia Hort. 94:219-229. 